\title{
Effects of insulin on long-term potentiation in hippocampal slices from diabetic rats
}

\author{
Y. Izumi ${ }^{1}$, K. A. Yamada ${ }^{2}$, M. Matsukawa ${ }^{1}$, C. F. Zorumski ${ }^{1}$ \\ ${ }^{1}$ Department of Psychiatry, Washington University School of Medicine, St. Louis, USA \\ ${ }^{2}$ Department of Neurology, Washington University School of Medicine, St. Louis, USA
}

\section{Abstract}

Aims/Hypothesis. Cognitive deficits occur commonly in diabetic patients. It is unclear whether these impairments result from hypoglycaemia during intensive insulin therapy, or from the diabetes itself. The aim of this study was to examine if impaired energy utilization resulting from insulin deficiency contributes to impaired long-term potentiation (reflecting impaired synaptic plasticity). As long-term potentiation is considered a candidate cellular mechanism underlying learning and memory, understanding how diabetes alters long-term potentiation may provide insight into mechanisms producing cognitive deficits in diabetes. Methods. Electrophysiologic recordings were used to study long-term potentiation in the CA1 region of hippocampal slices from healthy rats and rats with streptozotocin-induced diabetes.

Results. Long-term potentiation was difficult to induce in slices from diabetic rats in standard recording buffer (contains $10 \mathrm{mmol} / \mathrm{l}$ glucose). In slices from diabetic rats, increasing extracellular glucose failed to recover long-term potentiation induction, but $10 \mathrm{mmol} / \mathrm{l}$ pyruvate added to standard buffer enabled long-term potentiation induction. Moreover, incubation of slices from diabetic rats with insulin enabled long-term potentiation induction in standard buffer. Acute administration of streptozotocin alone did not impair long-term potentiation in slices from healthy animals, and changing extracellular glucose concentrations over the range of $5 \mathrm{mmol} / \mathrm{l}$ to $30 \mathrm{mmol} / \mathrm{l} \mathrm{did}$ not alter long-term potentiation in slices from control rats.

Conclusions/interpretation. These observations suggest that impaired energy utilization from insulin deficiency, rather than the accompanying hyperglycaemia, impair long-term potentiation in diabetes. Impaired hippocampal synaptic plasticity could contribute to learning and cognitive impairment in diabetic patients. [Diabetologia (2003) 46:1007-1012]

Keywords Diabetes, streptozotocin, hyperglycaemia, hippocampus, synaptic plasticity, pyruvate, glucose utilization.
Received: 19 September 2002 / Revised: 2 January 2003

Published online: 25 June 2003

C) Springer-Verlag 2003

Corresponding author: Dr. Y. Izumi, Department of Psychiatry, Washington University School of Medicine, $660 \mathrm{~S}$ Euclid Ave., BOX 8134, St. Louis, MO 63110, USA

E-mail: Izumiy@psychiatry.wustl.edu

Abbreviations: LTP, long-term potentiation; STZ, streptozotocin; AD, Alzheimer's type dementia; CNS, central nervous system; ACSF, artificial cerebrospinal fluid; PND, postnatal date; PS, population spike; CSF, cerebrospinal fluid; LTD, long-term synaptic depression.
Poor academic performance in diabetic children and memory impairment in adults with diabetes are viewed as increasing public health concerns. These problems are typically thought to result from hypoglycaemic attacks $[1,2]$, which occur more frequently during intensive insulin therapy [3]. Although insulininduced hypoglycaemia could contribute to learning problems [4], one recent prospective study did not find a relationship between severe hypoglycaemic events and cognitive impairment [5], raising the possibility that the diabetic condition alone might adversely affect learning and memory. Experimental evidence supporting an independent effect of diabetes upon 
brain function comes from studies showing that diabetic rats show memory impairment in the absence of insulin treatment or hypoglycaemia [6].

Experimental diabetes can be induced in rodents by treatment with streptozotocin (STZ), an agent that selectively destroys insulin-producing pancreatic beta cells. Rats treated with STZ show impairments in long-term potentiation (LTP) of hippocampal synaptic transmission, a form of synaptic plasticity thought to be involved in certain forms of memory processing. STZ-treated rats also show impaired performance in the Morris water-maze, a behavioural task that tests hippocampal-dependent spatial learning [6]. Previous studies suggest that hyperglycaemia is a principal cause of LTP impairment in STZ-treated rats because insulin therapy started immediately after STZ injection prevents the problem [6]. However, another study [7] found that hyperglycaemia induced by STZ paradoxically facilitates LTP induction in aged rats. As LTP induction is sensitive to changes in energy utilization $[8,9]$, it is possible that aging-induced changes in glucose use affect LTP induction. It has been suggested that Alzheimer's type dementia (AD) might represent a diabetes-like condition in the central nervous system (CNS) in which neuronal glucose utilization is impaired [10]. Consistent with this, poor glucose utilization is observed in the brains of $\mathrm{AD}$ patients [11, 12]. Furthermore, the beta amyloid protein that is involved in the pathophysiology of AD has been found to inhibit neuronal glucose utilization [13]. These observations raise the possibility that the LTP inhibition and memory impairment observed in rodents treated with STZ might not simply reflect the effects of hyperglycaemia or related complications. It is possible that poor energy utilization with an overabundance of glucose in the CNS results in cognitive dysfunction. Using hippocampal slices prepared from STZ-treated and healthy control rats, we examined possible mechanisms underlying changes in synaptic plasticity in diabetes.

\section{Materials and methods}

Animals. A single intraperitoneal (ip) injection of $60 \mathrm{mg} / \mathrm{kg}$ STZ (Sigma Chemical, St. Louis, Mo., USA), dissolved immediately before administration in $50 \mathrm{mmol} / \mathrm{l}$ citrate buffer, was given to male rats at postnatal day (PND) 30. All animal were allowed free access to water and laboratory food. Urine glucose was checked by Chemistrip uGK (Boehringer Mannheim) every 3 days until the time of hippocampal slice preparation. In some rats, blood and cerebrospinal fluid (CSF) were sampled prior to decapitation and a glucose oxidase method was utilized for assay of glucose. In control rats, the CSF/blood glucose ratio was greater than 0.6 [15].

Hippocampal slice preparation. Transverse slices were prepared from the septal half of the hippocampus using standard techniques [14]. Albino rats $(44 \pm 2$ days old) were anaesthetized with halothane and decapitated. The hippocampi were rapidly dissected at 4 to $6^{\circ} \mathrm{C}$ and cut into $500 \mu \mathrm{m}$ slices using a Campden vibrotome (Campden Instruments, Sileby, Loughborough, U.K.). Slices were then kept in artificial cerebrospinal fluid (ACSF) containing (in millimolar): $124 \mathrm{NaCl}, 5 \mathrm{KCl}$, $2 \mathrm{MgSO}_{4}, 2 \mathrm{CaCl}_{2}, 1.25 \mathrm{NaH}_{2} \mathrm{PO}_{4}, 22 \mathrm{NaHCO}_{3}, 10$ glucose, bubbled with $95 \% \mathrm{O}_{2}-5 \% \mathrm{CO}_{2}$ in an incubation chamber for at least $60 \mathrm{~min}$ at $30^{\circ} \mathrm{C}$.

Electrophysiology. For synaptic experiments, slices were transferred to a submersion recording chamber where they were continuously perfused with $\mathrm{ACSF}(2 \mathrm{ml} / \mathrm{min})$ at $30^{\circ} \mathrm{C}$. Extracellular recordings were obtained from the pyramidal cell layer and dendritic region of CA1 using 5 to $10 \mathrm{M} \Omega$ electrodes filled with $2 \mathrm{M} \mathrm{NaCl}$. During an experiment, the Schaffer collateralcommissural fibres were stimulated in stratum radiatum with bipolar electrodes and 0.1 to $0.2 \mathrm{~ms}$ constant current pulses at an intensity sufficient to evoke a $50 \%$ maximal population spike (PS) based on a baseline stimulus-response curve. Halfmaximal stimulus intensities allow easy and reliable detection of changes in synaptic transmission. The initial slope of the EPSP was used for data analysis. The average slope of the EPSPs during a $20 \mathrm{~min}$ baseline recording period was used to normalize the EPSP slopes for comparison among slices. The EPSP slopes are shown as a percentage of the average baseline EPSP slope. LTP was induced using a single $1 \mathrm{sec}$ tetanus at $100 \mathrm{~Hz}$. Potentiation of the EPSP slope by more than $20 \%$ 60 minutes after tetanic stimulation was considered to represent successful induction and maintenance of LTP. Only a single slice from each hippocampus was used for each group of experiments. Values in the text represent means \pm SE, unless otherwise noted. Chemicals were obtained from Sigma-Aldrich.

Statistical analysis. Data in the text and figures are expressed as means \pm SEM. The Mann-Whitney U test and Student's $t$ test were used for comparisons between groups. A p value of less than 0.05 was considered statistically significant.

\section{Results}

In nine of eleven rats treated with STZ, a diabetic state was established within 2 weeks as characterized by glycosuria and hyperglycaemia. Final blood glucose concentrations obtained at the time of preparation of hippocampal slices were $401 \pm 170 \mathrm{mg} / \mathrm{dl}$ (mean \pm S.D., $n=11$ ). We excluded two rats from the study because they had normal blood glucose concentrations $(<200 \mathrm{~g} / \mathrm{dl})$ at the time of dissection. Final blood glucose concentrations in the nine diabetic rats were $456 \pm 130 \mathrm{~g} / \mathrm{dl}$. Body weights were $120 \pm 63 \mathrm{~g}$ for diabetic rats and $163 \pm 26 \mathrm{~g}$ for control rats.

As reported by other investigators, LTP was difficult to induce in hippocampal slices from STZ-treated rats with $10 \mathrm{mmol} / \mathrm{l}$ glucose using a stimulation protocol that reliably generates LTP in slices from control rats $(+5.1 \pm 2.6 \%$ change in EPSP slopes in diabetic rats, $n=9$ vs $+41.3 \pm 6.3 \%$ increase in EPSPs in matched controls, $n=5, p=0.001$ ) [6]. This failure of LTP induction does not result from direct effects of STZ because acute administration of STZ $(60 \mathrm{mg} / \mathrm{l})$ for $30 \mathrm{~min}$ did not alter either basal synaptic transmission or induction of LTP (Fig. 1). 


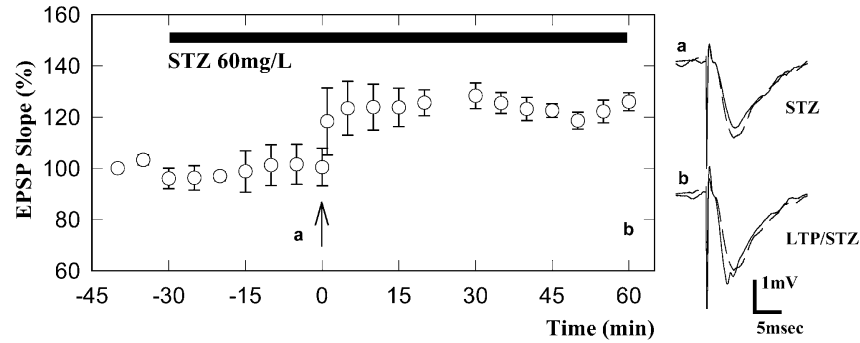

Fig. 1A, B. STZ does not acutely inhibit LTP induction in hippocampal slices from control rats. The graph shows the time course of change in field EPSP slope normalized with respect to initial baseline responses $(100 \%)$. The traces to the right of the graph show representative EPSPs obtained 40 min before (dashed traces), just prior to tetanic stimulation (A) and 60 min after tetanic stimulation (B). The dashed trace is the baseline and the trace following treatment is shown as a continuous line. Basal synaptic transmission was not affected by 15 min perfusion of $60 \mathrm{mg} / \mathrm{L} \mathrm{STZ}$. Administration of STZ (filled bar) prior to tetanic stimulation (arrow) did not inhibit LTP induction

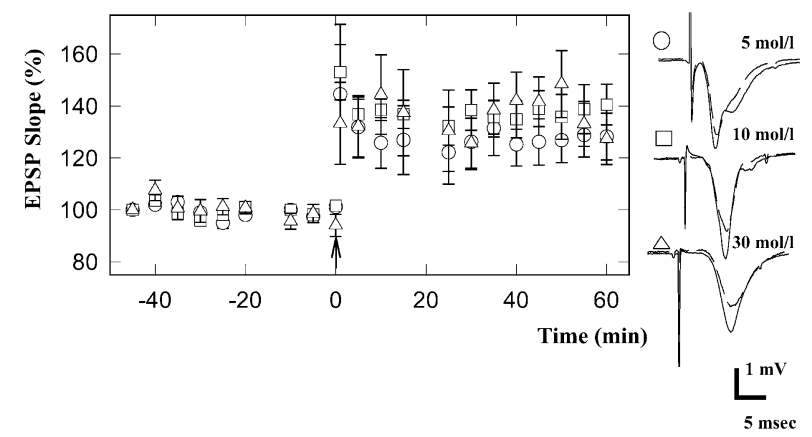

Fig. 2. High concentrations of glucose do not alter LTP induction in slices from healthy rats. LTP induction was not altered by raising extracellular glucose from $5 \mathrm{mmol} / \mathrm{l}$ (open circles) to $10 \mathrm{mmol} / \mathrm{l}$ (open squares) or $30 \mathrm{mmol} / 1$ (open triangles). The glucose concentration was changed from $10 \mathrm{mmol} / \mathrm{l}$ to $5 \mathrm{mmol} / \mathrm{l}$ or $30 \mathrm{mmol} / \mathrm{l}$ prior to tetanic stimulation. The traces to the right of the graph show representative EPSPs obtained $45 \mathrm{~min}$ before (dashed lines) and $60 \mathrm{~min}$ after tetanic stimulation (solid lines)

It is possible that the difficulty with LTP induction in diabetic rats results from excessive extracellular glucose. However, in hippocampal slices from healthy rats, changing the extracellular glucose concentration over the range of 5 to $30 \mathrm{mmol} / \mathrm{l}$ did not alter LTP induction (Fig. 2). As LTP is typically studied with $10 \mathrm{mmol} / \mathrm{l}$ glucose and diabetic rats have blood glucose concentrations that exceed this concentration, it is possible that $10 \mathrm{mmol} / \mathrm{l}$ glucose represents a relatively low glucose concentration in slices from diabetic rats. To examine this, the extracellular glucose concentration was increased to $30 \mathrm{mmol} / \mathrm{l}$ in slices from STZ-treated rats, a concentration comparable to blood glucose concentrations observed in these animals. Slices were exposed to $30 \mathrm{mmol} / \mathrm{l}$ glucose starting at the time of hippocampal slice preparation. De-

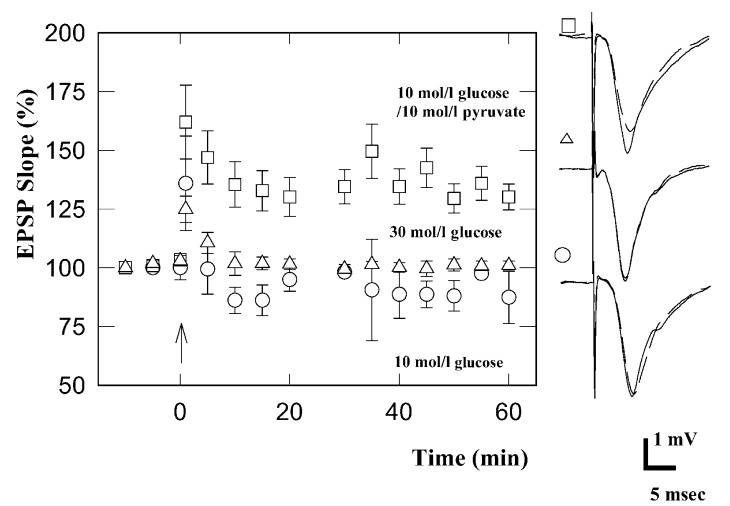

Fig. 3. Inhibition of LTP induction in slices from diabetic rats and the effects of pyruvate. In slices from diabetic rats, LTP was not induced by tetanic stimulation (arrow) with $10 \mathrm{mmol} / \mathrm{l}$ glucose (open circles) or $30 \mathrm{mmol} / \mathrm{l}$ glucose (open triangles). In the existence of $10 \mathrm{mmol} / \mathrm{l}$ pyruvate plus $10 \mathrm{mmol} / \mathrm{l}$ glucose, however, LTP was induced (open squares). The traces to the right of the graph show representative EPSPs obtained prior to (dashed lines) and 60 min after tetanic stimulation (solid lines)

spite high glucose concentrations in the ACSF, LTP still could not be induced in slices from STZ-treated rats (Fig. 3). These observations suggest that the failure of LTP induction in diabetic rats does not result from high glucose. In three of the nine diabetic rats studied, we sampled cerebrospinal fluid CSF before decapitation. CSF glucose concentrations were $151 \pm 47 \mathrm{mg} / \mathrm{dl}$, while blood glucose concentrations were $386 \pm 54 \mathrm{mg} / \mathrm{dl}$ with a $\mathrm{CSF} / \mathrm{blood}$ ratio of $0.39 \pm 0.06(n=3)$. This $\mathrm{CSF} / \mathrm{blood}$ glucose ratio was lower than the ratio in control rats $(0.6, p=0.005)$.

Although increases in extracellular glucose concentration did not permit LTP induction in slices from STZ-treated animals, it is possible that altered energy use is an important factor underlying the failure of LTP. As we previously observed that pyruvate can serve as an alternative energy substrate for LTP induction, we examined whether addition of pyruvate to the extracellular medium altered the generation of synaptic plasticity. Addition of $10 \mathrm{mmol} / \mathrm{l}$ pyruvate to $10 \mathrm{mmol} / \mathrm{l}$ glucose reliably allowed LTP in slices from STZ-treated rats $(+32.3 \pm 6.7 \%, n=5$ By U test $p=0.005$ compared to glucose alone). However, LTP was not induced with $10 \mathrm{mmol} / \mathrm{l}$ or $20 \mathrm{mmol} / \mathrm{l}$ pyruvate alone (changes in EPSPs: $-1.8 \pm 6.2 \%, n=3 ;+3.7 \pm 9.1 \%, n=3$, respectively, data not shown). In control slices, $10 \mathrm{mmol} / \mathrm{l}$ pyruvate did not augment EPSPs with $10 \mathrm{mmol} / \mathrm{l}$ glucose, and LTP induced under these conditions was comparable to control LTP with $10 \mathrm{mmol} / \mathrm{l}$ glucose without pyruvate (changes in EPSPs: $+34.1 \pm$ $5.5 \%, n=4$ pyruvate plus glucose; $36.5 \pm 4.1 \%, n=5$ glucose without pyruvate, data not shown). These results indicate that the recovery of LTP in STZ-treated rats does not result from potentiation of synaptic responses or LTP by pyruvate, but rather that defective energy metabolism is likely to be involved in the failure to generate LTP. Although pyruvate can overcome 


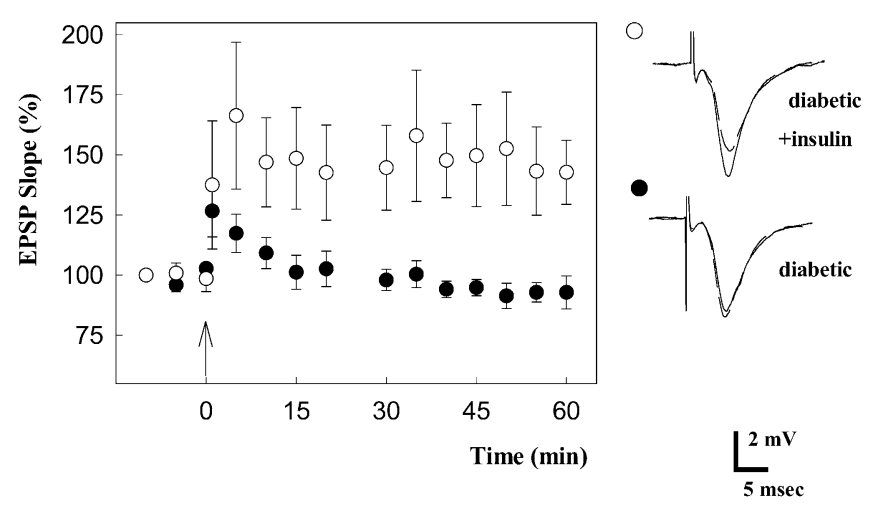

Fig. 4. Insulin overcomes the failure of LTP induction in slices from diabetic rats. In the existence of $10 \mathrm{mmol} / \mathrm{l}$ glucose, the failure of LTP induction in slices from diabetic rats (filled circles) was overcome by administration of $1 \mu \mathrm{mol} / \mathrm{l}$ insulin (open circles). The traces to the right of the graph show representative EPSPs obtained prior to (dashed lines) and $60 \mathrm{~min}$ after tetanic stimulation (solid lines). Insulin was administered from the time of dissection and was continued throughout the experiments

this defect, recovery of LTP by pyruvate in STZ-treated rats remains dependent upon the presence of extracellular glucose.

Insulin deficiency or lack of insulin activity is likely to contribute to poor glucose utilization in STZtreated rats. Increasing evidence suggests that insulin has direct actions in the CNS and modulates synaptic transmission. To examine the role of insulin deficiency in the failure of LTP induction, insulin was administered to slices starting at the time of dissection (Fig. 4). Slices were incubated with $1 \mu \mathrm{mol} / \mathrm{l}$ insulin until the time of experiment (for $\sim 2-3 \mathrm{~h}$ in total). We also continuously administered $1 \mu \mathrm{mol} / \mathrm{l}$ insulin throughout these experiments. In the existence of insulin and $10 \mathrm{mmol} / \mathrm{l}$ glucose, LTP was consistently induced in slices from STZ-treated rats (changes in EPSPs: $+41.5 \pm 10.2 \%, n=9 ; p=0.008$ by $\mathrm{U}$ test compared to no insulin). The degree of LTP was comparable to that in control slices incubated with $1 \mu \mathrm{mol} / 1$ insulin (EPSP changes: $+44.6 \pm 8.3, n=5$, data not shown).

\section{Discussion}

Several studies have raised concerns about the effects of diabetes on memory and learning in children [2, 16, 17, 18]. Additionally, memory impairment has been observed in older adults with diabetes [19] and in diabetics with hypertension [20]. There is also evidence for an increased incidence of dementia in diabetic patients $[21,22,23]$. The mechanisms underlying these cognitive deficits remain uncertain with concerns being raised about the effects of insulin/ hypoglycaemic therapies and the underlying illness itself [4, 24].
In efforts to develop an animal model for studying cognitive impairment in diabetic patients, it has been observed that rats treated with STZ develop a diabetes-like state and show altered synaptic plasticity and learning. LTP is widely considered to be a synaptic model for the information processing that underlies certain forms of memory and learning, and a correlation between changes in LTP and impaired performance in tests of spatial learning has been reported in a number of studies. Similarly, a correlation between diminished LTP induction or maintenance and poor performance in the spatial memory version of the Morris water-maze test has been observed in diabetic rats [25]. This suggests that understanding how defects in LTP occur could help to explain mechanisms involved in learning difficulties in diabetic patients.

In animals rendered diabetic by treatment with STZ, there are several potential mechanisms that could contribute to defects in LTP and learning. One possibility is that STZ directly impairs synaptic function. This seems unlikely because the failure of LTP induction has previously been correlated with the development of abnormal glucose concentrations rather than with STZ administration itself [6]. In our studies, acute administration of STZ to hippocampal slices did not impair either basal transmission or LTP induction in slices from healthy rats. Furthermore, intensive insulin treatment that normalizes blood glucose concentrations prevents the failure of LTP induction in STZrats, suggesting that it is the diabetic state itself that is responsible for the inhibition of LTP [6].

Although diabetes is primarily recognized on the basis of hyperglycaemia, STZ injections lead to insulin deficiency as well as poor glucose utilization. Thus, hyperglycaemia per se might not be the cause of LTP failure. Indeed, we observed that increasing glucose concentrations up to $30 \mathrm{mmol} / \mathrm{l}$ did not impair LTP in slices from healthy rats. Additionally, the standard glucose concentration $(10 \mathrm{mmol} / \mathrm{l})$ used for hippocampal slice recording is high relative to physiological levels in brain extracellular fluid and did not permit LTP induction in slices from STZ-treated animals. These observations suggest that the failure of LTP in slices from diabetic rats does not result from increased glucose concentrations. Interestingly, glucose concentrations in the CSF of diabetic rats were not as high as expected from the blood concentrations. Although the $\mathrm{CSF} /$ blood glucose ratio is normally about 0.67 , the ratio is altered in diabetic patients and is often considerably less than 0.6 [26]. The relatively low CSF/ blood glucose ratio in diabetic patients could result from down-regulation of blood-brain barrier glucose transporters $[27,28]$.

The role of insulin deficiency in the failure of synaptic plasticity is also important to consider. Although it has long been thought that the brain is an insulin insensitive organ [29], recent evidence suggests otherwise. Insulin can be transported from plasma into 
brain through the blood brain barrier, achieving concentrations of about $3 \mathrm{pmol} / \mathrm{l}$ in the CNS $[30,31]$. The existence of insulin receptors [32, 33] and GLUT-4, an insulin-sensitive glucose transporter [34, 35, 36], in the CNS supports the idea that insulin can exert direct actions in the CNS. Pre-incubation with insulin promotes survival of cultured neurons during glucose deprivation by facilitating glial glycogen synthesis [37]. In the hippocampus, insulin has several effects on cellular and synaptic function. In addition to effects on energy metabolism, insulin acutely inhibits spontaneous firing of pyramidal neurons [38], increases functional postsynaptic GABA receptors [39], and rapidly potentiates NMDA receptor-mediated EPSPs [40]. Furthermore, insulin-mediated tyrosine kinase activation phosphorylates NMDA receptors [41] and insulin can produce a form of long-term synaptic depression (LTD) in the CA1 region resulting from a decrease in membrane expression of AMPA-type glutamate receptors [42]. Although NMDA receptors are altered several months after STZ injection [43], this effect is unlikely to contribute to the failure of LTP induction in this study because we used rats 2 weeks after STZ injection. These observations make it reasonable to consider whether previously described effects of intensive insulin therapy on LTP induction result from direct effects of insulin in the CNS rather than correction of plasma glucose concentrations [25]. In our experiments, the ability to induce LTP in the presence of insulin in slices from STZ-treated animals suggests that insulin deficiency, rather than hyperglycaemia, contributes to the failure of LTP induction.

Although insulin has multiple actions in the CNS, our results suggest that insulin deficiency impairs energy metabolism and contributes to failure of LTP induction. We base this conclusion on the ability of pyruvate to promote recovery of LTP in slices from STZ-treated rats. Pyruvate, a monocarboxylate that can serve as an energy substrate in the CNS [44, 45], is transported into neurons through monocarboxylate transporters (MCTs) that are highly expressed in the hippocampus [46]. In slices from healthy rats, pyruvate alone supports LTP induction even without glucose [9]. However, pyruvate alone was not sufficient to support LTP induction in slices from STZ-treated rats, suggesting that its use as an energy substrate could also be impaired under diabetic conditions. Impaired glucose utilization in the brain [47] might be explained by depressed activity of glycolytic enzymes [48] or glucose transporters. In the hippocampus from diabetic rats, GLUT3, the neuron specific glucose transporter, shows increased protein conjugation by a lipid peroxidation product [49], possibly reducing neuronal glucose uptake.

A limitation of our study is that the duration of diabetes was only about 2 weeks. It will be important in future studies to address the question of whether insulin and pyruvate are effective in restoring LTP induc- tion when the diabetic state is longer standing. In previous studies, systemic insulin failed to promote LTP induction when insulin administration was delayed following STZ injection [25].

Acknowledgements. We thank M. Izumi and A. Benz for technical support. This study was supported by NIH DK20579, DK56341, MH45493, AG18434, AA12951, The University of Missouri's Alzheimer's Disease and Related Disorders program and the Bantly Foundation.

\section{References}

1. Golden MP, Ingersoll GM, Brack CJ, Russell BA, Wright JC, Huberty TJ (1989) Longitudinal relationship of asymptomatic hypoglycemia to cognitive function in IDDM. Diabetes Care 12:89-93

2. Ryan C, Atchison J, Puczynski S, Puczynski M, Arslanian S, Becker D (1990) Mild hypoglycemia associated with deterioration of mental efficiency in children with insulindependent diabetics mellitus. J Pediatr 117:32-38

3. The Diabetes Control and Complications Trial Research Group (1997) Hypoglycemia in the Diabetes Control and Complications Trial. Diabetes 46:271-286

4. Northam EA, Anderson PJ, Jacobs R, Hughes M, Warne GL, Werther GA (2001) Neuropsychological profiles of children with type 1 diabetes 6 years after disease onset. Diabetes Care 24:1541-1546

5. Schoenle EJ, Schoenle D, Molinari L, Largo RH (2002) Impaired intellectual development in children with Type I diabetes: association with $\mathrm{HbA}(1 \mathrm{c})$, age at diagnosis and sex. Diabetologia 45:108-114

6. Biessels GJ, Kamal A, Ramakers GM, Urban IJ, Spruijt BM, Erkelens WD, Gispen WH (1996) Place learning and hippocampal synaptic plasticity in streptozotocin-induced diabetic rats. Diabetics 45:1259-1266

7. Tekkok S, Krnjevic K (1999) Diabetes mellitus preserves synaptic plasticity in hippocampal slices from middle-aged rats. Neuroscience 91:185-191

8. Izumi Y, Zorumski CF (1997) Involvement of nitric oxide in low glucose-mediated inhibition of hippocampal longterm potentiation. Synapse 25:258-262

9. Izumi Y, Katsuki H, Zorumski CF (1997) Monocarboxylates (pyruvate and lactate) as alternative energy substrates for the induction of long-term potentiation in rat hippocampal slices. Neurosci Lett 232:17-20

10. Hoyer S (2000) Brain glucose and energy metabolism abnormalities in sporadic Alzheimer disease. Causes and consequences: an update. Exp Gerontol 35:1363-1372

11. Hoyer S (1993) Abnormalities in brain glucose utilization and its impact on cellular and molecular mechanisms in sporadic dementia of Alzheimer type. Ann NY Acad Sci 695:77-80

12. Fukuyama H, Ogawa M, Yamauchi H, Yamaguchi S, Kimura J, Yonekura Y, Konishi J (1994) Altered cerebral energy metabolism in Alzheimer's disease: a PET study. J Nucl Med 35:1-6

13. Uemura E, Greenlee HW (2001) Amyloid beta-peptide inhibits neuronal glucose uptake by preventing exocytosis. Exp Neurol 170:270-276

14. Zorumski CF, Mennerick S, Izumi Y (1996) Assessment of synaptic effects of nitric oxide in hippocampal neurons. Methods Neurosci 31:283-299 
15. Izumi Y, Ishii K, Katsuki H, Benz AM, Zorumski CF (1998) $\beta$-Hydroxybutyrate fuels synaptic function during development. Histological and physiological evidence in rat hippocampal slices. J Clin Invest 101:1121-1132

16. Rovet J, Ehrlich R, Hoppe M (1987) Behavior problems in children with diabetes as a function of sex and age of onset of disease. J Child Psychol Psychiatry 28:477-491

17. Crawford SG, Kaplan BJ, Field LL (1995) Absence of an association between insulin-dependent diabetes mellitus and developmental learning difficulties. Hereditas 122:7378

18. McCarthy AM, Lindgren S, Mengeling MA, Tsalikian E, Engvall JC (2002) Effects of diabetes on learning in children. Pediatrics 109:E9

19. Reaven GM, Thompson LW, Nahum D, Haskins E (1990) Relationship between hyperglycemia and cognitive function in older NIDDM patients. Diabetes Care 13:16-21

20. Elias PK, Elias MF, D'Agostino RB, Cupples LA, Wilson PW, Silbershatz H, Wolf PA (1997) NIDDM and blood pressure as risk factors for poor cognitive performance. The Framingham Study. Diabetes Care 20:1388-1395

21. Kalmijn S, Feskens EJ, Launer LJ, Stijnen T, Kromhout D (1995) Glucose intolerance, hyperinsulinaemia and cognitive function in a general population of elderly men. Diabetologia 38:1096-1102

22. Vanhanen M, Koivisto K, Kuusisto J, Mykkanen L, Helkala EL, Hanninen T, Riekkinen P, Soininen H, Laakso M (1998) Cognitive function in an elderly population with persistent impaired glucose tolerance. Diabetes Care 21:398-402

23. Sinclair AJ, Allard I, Bayer A (1997) Observations of diabetes care in long-term institutional settings with measures of cognitive function and dependency. Diabetes Care 20:778-784

24. Hershey T, Bhargava N, Sadler M, White NH, Craft S (1999) Conventional versus intensive diabetes therapy in children with type 1 diabetes: effects on memory and motor speed. Diabetes Care 22:1318-1324

25. Biessels GJ, Kamal A, Urban IJ, Spruijt BM, Erkelens DW, Gispen WH (1998) Water maze learning and hippocampal synaptic plasticity in streptozotocin-diabetic rats: effects of insulin treatment. Brain Res 800:125-135

26. Powers WJ (1981) Cerebrospinal fluid to serum glucose ratios in diabetes mellitus and bacterial meningitis. Am J Med 71:217-220

27. Gjedde A, Crone C (1981) Blood-brain glucose transfer: repression in chronic hyperglycemia. Science 214:456-457

28. Pardridge WM, Triguero D, Farrell CR (1990) Downregluation of blood-brain barrier glucose transporter in experimental diabetes. Diabetes 39:1040-1044

29. Lund-Andersen H (1979) Transport of glucose from blood to brain. Physiol Rev 59:305-352

30. Baura GD, Foster DM, Prote D Jr, Kahn S, Bergman RN, Cobelli C, Schwartz MW (1993) Saturable transport of insulin from plasma into the central nervous system of dogs in vivo. A mechanism for regulated insulin delivery to the brain. J Clin Invest 92:1824-1830

31. Baskin DG, Figlewicz DP, Woods SC, Porte D Jr, Dorsa DM (1987) Insulin in the brain. Ann Rev Physiol 49:335-347

32. Zahniser NR, Goens MB, Hanaway PJ, Vinych JV (1984) Characterization and regulation of insulin receptors in rat brain J Neurochem 42:1354-1362
33. Adamo M, Raizada MK, LeRoith D (1989) Insulin and insulin-like growth factor receptors in the nervous system. Mol Neurobiol 3:71-100

34. Unger J, McNeil TH, Moxley RT 3rd, White M, Moss A, Livingston JN (1989) Distribution of insulin receptor-like immunoreactivity in the rat forebrain. Neurosci 31:143-157

35. Leloup C, Arlusion M, Kasis N, Lepetti N, Cartier N, Ferre P, Penicaud L (1996) Discrete brain areas express the insulin-responsive glucose transporter GLUT4. Mol Brain Res 38:45-53

36. El Messari S, Ait-Ikhlef A, Ambroise DH, Penicaud L, Arluison M (2002) Expression of insulin-responsive glucose transporter GLUT4 mRNA in the rat brain and spinal cord: an in situ hybridization study. J Chem Neuroanat 24:225-242

37. Swanson RA, Choi DW (1993) Glial glycogen stores affect neuronal survival during glucose deprivation in vitro. J Cereb Blood Flow Metab 13: 162-169

38. Palovcik RA, Phillips MI, Kappy MS, Raizada MK (1984) Insulin inhibits pyramidal neurons in hippocampal slices. Brain Res 309:187-191

39. Wan Q, Xiong ZG, Man HY, Ackerley CA, Braunton J, Lu WY, Becker LE, MacDonald JF, Wang YT (1997) Recruitment of functional GABA (A) receptors to postsynaptic domains by insulin. Nature 388:686-690

40. Liu L, Brown JC 3rd, Webster WW, Morrisett RA, Monaghan DT (1995) Insulin potentiates N-methylD-aspartate receptor activity in Xenopus oocytes and rat hippocampus. Neurosci Lett 192:5-8

41. Christie JM, Wenthold RJ, Monaghan DT (1999) Insulin causes a transient tyrosine phosphorylation of NR2A and NR2B NMDA receptor subunits in rat hippocampus. J Neurochem 72:1523-1528

42. Man HY, Lin JW, Ju WH, Ahmadian G, Liu L, Becker LE, Sheng M, Wang YT (2000) Regulation of AMPA receptormediated synaptic transmission by clathrin-dependent receptor internalization. Neuron 25:649-662

43. Gardoni F, Kamal A, Bellone C, Biessels GJ, Ramakers GMJ, Cattabeni F, Gispen WH, Di Luca M (2002) Effects of streptozotocin-diabetes on the hippocampal NMDA receptor complex in rats. J Neurochem 80:438-447

44. Izumi Y, Benz AM, Zorumski CF, Olney JW (1994) Effects of lactate and pyruvate on glucose deprivation in rat hippocampal slices. Neuroreport 5:617-620

45. Izumi Y, Benz AM, Katsuki H, Zorumski CF (1997) Endogenous monocarboxylates sustain hippocampal synaptic function and morphological integrity during energy deprivation. J Neurosci 17:9448-9457

46. Koehler-Stec EM, Simpson IA, Vannucci SJ, Landschulz KT, Landschulz WH (1998) Monocarboxylate transporter expression in mouse brain. Am J Physiol 275:E516-524

47. McCall AL (1992) The impact of diabetes on the CNS. Diabetes 41:557-570

48. Plaschke K, Hoyer S (1993) Action of the diabetogenic drug streptozotocin on glycolytic and glycogenolytic metabolism in adult rat brain cortex and hippocampus. Int J Dev Neurosci 11:477-483

49. Reagan LP, Magarinos AM, Yee DK, Swzeda LI, Van Bueren A, McCall AL, McEwen BS (2000) Oxidative stress and HNE conjugation of GLUT3 are increased in the hippocampus of diabetic rats subjected to stress. Brain Res 862:292-300 